\title{
Comparing Hospital Infections in the Elderly versus Younger Adults: An Experience in a Brazilian University Hospital
}

\author{
Rosineide M. Ribas and Paulo P. Gontijo Filho
}

Uberlandia Federal University

\begin{abstract}
The elderly population will grow rapidly over the next 25 years, however there is little information about hospital infections in this group of patients in Brazil. We examined the prevalence of nosocomial and community infections in elderly ( $\geq 65$ years) patients and their relationship with intrinsic and extrinsic risk factors in a Brazilian University Hospital. A total of 155 hospitalized elderly patients were evaluated, and clinical and demographic information about each patient was obtained from hospital records. The rates of nosocomial and community infections were $16.1 \%$ and $25.6 \%$, respectively. When the elderly group with and without nosocomial infections was analyzed, practically all the risk factors considered (use of antibiotics, invasive devices, surgery and time of hospitalization) were significantly more associated with the patients with hospital infection. All patients with nosocomial infections were taking antibiotics and most of them $(56.0 \%)$ were being treated with two or more antibiotics; the length of hospitalization was double $(p=0.007)$ compared to patients who had not acquired hospital infection. The most frequent sites of nosocomial and community infections were surgical $(56.0 \%)$ and the skin $(37.1 \%)$, and most of the patients $(\mathbf{4 7 . 5 \%})$ were in the surgical clinic wards. In conclusion, the elderly patients were more likely to develop a nosocomial infection (16.1\% prevalence). Surgical infection accounted for the majority $\mathbf{5 6 . 0 \%}$ ) of the nosocomial infections, in contrast with North American studies that indicate urinary tract infections to be the commonest.
\end{abstract}

Key Words: Elderly, nosocomial infections, risk factors, Brazilian hospitals, infection control.

Infections in elderly patients are a growing challenge for clinical microbiologists, clinicians and medical administrators. Generally, the elderly have greater susceptibility to infections than do younger adults. It is well known that aging is associated with immune dysfunction, frequency of diabetes mellitus, prolonged hospitalization and use of antimicrobial agents [1-3].

Nosocomial infections in developing countries are a major public health problem that are often not recognized [4]. In developed countries, the proportion

Received on 16 July 2002; revised 01 April 2003.

Address for correspondence: Dr. Paulo Gontijo. Area of Immunology, Microbiology and Parasitology, Uberlandia Federal University. Campus Umuarama, Zip code: $38400-902$, Uberlândia-MG, Brazil.E-mail: rosi_ribas@yahoo.com.br / Phone: (0xx34) 3236-8551. E-mail: gontijofilho@ufu.br / telephone: (0xx34) 3218-2236.

The Brazilian Journal of Infectious Diseases 2003;7(3):210-215 (C) 2003 by The Brazilian Journal of Infectious Diseases and Contexto Publishing. All rights reserved. of elderly people in the general population and among those hospitalized has been increasing [4]

We evaluated the prevalence of nosocomial infections in elderly and younger adult patients, and associations with intrinsic and extrinsic risk factors in a Brazilian University Hospital.

\section{Materials and Methods}

Patients. We studied 495 hospitalized adults (14 - 64years old) and 155 hospitalized elderly patients (older than 65 years) at the Uberlandia Federal University Hospital, which is a teaching hospital with a 450-bed capacity that offers tertiary care.

Study design. During the project three repeated prevalence investigations were carried out in January/ 1999, February/2000 and October/2000 in all medical and surgical units. Clinical and demographic information about each patient, including intrinsic (age and time of 
hospitalization) and extrinsic risk factors (surgery, invasive procedures and use of antimicrobial agents), was obtained from hospital records. The infections were classified by using a set of predetermined definitions of community infections and hospital infections from the Center for Disease Control (CDC, Atlanta, GA)

Statistical methods. All data were analyzed using epiinfo version 5.0. Categorical variables were compared using the likelihood ratio test, or when appropriate, Fisher's exact test. Odd Ratios (OR) and 95\% confidence intervals (CI 95\%) were calculated [5].

Study approval. This study was approved by the Ethics Committee of the Hospital de Clinicas in UberlandiaMG, Brazil.

\section{Results}

The hospital-acquired infection rates in adults (less than 65 years old) and elderly patients were $14.5 \%$ and $16.1 \%$, respectively, and the prevalence of community infections was also similar in these two groups (25.0\% vs. 25.6\%).

The association of nosocomial infections with intrinsic and extrinsic risk factors was similar (Table 2). When only the elderly group was analyzed, practically all the risk factors considered were associated with hospital infection (Table 3). Though they were associated with nosocomial infections in both adults and elderly individuals, the use of $\geq 2$ invasive devices $(76.4 \%$ vs. $56.0 \%)$ and surgery $(70.8 \%$ vs. $60.0 \%)$ were not significantly different $(>0.05)$.

The prevalence rates in males versus females were similar, with 47:25 in the adults and 17:8 in the elderly, respectively. The median age of adult patients was 40.5 \pm 14.6 (range 14 to 64 years) and $73.0 \pm 7.2$ years (range 65 to 94 years) in the elderly patients. There was no significant difference in the duration of hospitalization between adults and elderly patients ( 24.5 \pm 19.4 vs $18.5 \pm 17.6$, respectively). The latter group remained hospitalized for one to 92 days. All patients with nosocomial infections were taking antibiotics and most $(84.2 \%)$ of those in the elderly group were being treated with two or more antibiotics (Table 2).

Most of the patients with nosocomial infections were in surgical wards (66.7\% adults vs. $56.0 \%$ elderly) and only $8.0 \%$ of the elderly patients were in the Intensive Care Unit (Table 4).

The most frequent site of nosocomial infections in both groups was surgical incisions (47.2\% vs. $56.0 \%)$, in the adults and the elderly, respectively, and the lungs ( $27.8 \%$ vs. $24.0 \%$ ), while the most common community infections were in the lungs $(21.8 \%$ vs. $25.7 \%)$ and on the skin $(34.7 \%$ vs. $37.1 \%)$ (Table 5).

\section{Discussion}

The challenges of infectious diseases in geriatric patients are growing rapidly because of the rapidly expanding proportion of elderly persons in the general population. The increasing numbers of persons $\geq 65$ years of age form a population especially at risk for nosocomial infections. Recent data from the National Nosocomial Infections Surveillance (NNIS) study indicate that $54.0 \%$ of infections in adults appeared in patients 65 years of age or older [6]. The vulnerability of this age group is related to impaired host defenses, chronic underlying disease, poor tolerance to therapeutic procedures, increased time of hospitalization and use of antimicrobial agents [2,7].

In spite of their importance, very little is known about the incidence, risk factors and type of Hospital Acquired Infections (HAI) in the elderly. In Brazil, as in Mexico, most medical attention depends on governmental institutions and infection control polices have to face two crucial problems: limited resources for health care and lack of awareness of the importance of prevention of nosocomial infections [8].

Although several studies have shown that morbidity and mortality from hospital infections is higher in elderly persons than in younger patients [3,9], our data from both hospital (14.5\% vs. 16.1\%) and community acquired infections ( $25.0 \%$ vs. $25.6 \%)$ in the adults and the elderly, respectively,indicated no difference between these groups. These results corroborate our data that show no differences in the intrinsic and 
Table 1. Characteristics of hospitalized (under 65) adults and elderly patients at the Hospital das Clinicas, Universidade Federal de Uberlandia (UFU-HC), defined by surveillance in the wards

\begin{tabular}{lccccc}
\hline Characteristics & $\begin{array}{c}\text { Adults } \\
\mathbf{N}=\mathbf{4 9 5}(\boldsymbol{\%})\end{array}$ & $\begin{array}{c}\text { Elders } \\
\mathbf{N}=\mathbf{1 5 5}(\boldsymbol{\%})\end{array}$ & $\mathbf{P}$ & OR & CI \\
\hline $\begin{array}{l}\text { Age (years) } \\
\text { Antibiotics: }\end{array}$ & $40.5 \pm 14.2$ & $73.6 \pm 6.8$ & $<0.0001$ & - & - \\
$\quad$ Yes & $242(48.9)$ & $65(41.9)$ & 0.15 & 1.32 & $0.91-1.94$ \\
$\quad \mathrm{~N} \geq 2$ & $113(22.8)$ & $24(15.5)$ & 0.06 & 1.61 & $0.97-2.70$ \\
$\quad \begin{array}{l}\text { Invasive devices: } \\
\quad \text { N } \geq 2\end{array}$ & $137(27.7)$ & $53(34.2)$ & 0.14 & 0.74 & $0.49-1.10$ \\
Surgery & $145(28.5)$ & $57(36.8)$ & 0.09 & 0.71 & $0.48-1.06$ \\
\hline
\end{tabular}

$\mathrm{P}$ - probability of a difference; OR - odds ratio; CI - Confidence Intervals.

Table 2. Risk factors of adults and elderly patients hospitalized with nosocomial infections at the UFU-HC, during January/1999, February/2000 and October/2000

\begin{tabular}{|c|c|c|c|c|c|}
\hline Risk Factors & $\begin{array}{c}\text { Adults } \\
\mathrm{N}=72(\%)\end{array}$ & $\begin{array}{c}\text { Elders } \\
\mathrm{N}=25(\%)\end{array}$ & $\mathbf{P}$ & OR & CI \\
\hline \multicolumn{6}{|l|}{ Intrinsic } \\
\hline \multicolumn{6}{|l|}{ Sex: } \\
\hline Female & $25(34.7)$ & $8(32.0)$ & 0.99 & 1.13 & $0.39-3.34$ \\
\hline Male & $47(65.3)$ & $17(68.0)$ & & & \\
\hline Age (years) & $40.4 \pm 14.6$ & $73.0 \pm 7.2$ & $<0.0001$ & - & - \\
\hline $\begin{array}{l}\text { Duration of } \\
\text { hospitalization (days) }\end{array}$ & $24.5 \pm 19.4$ & $18.5 \pm 17.6$ & 0.18 & - & - \\
\hline \multicolumn{6}{|l|}{ Extrinsic } \\
\hline \multicolumn{6}{|l|}{ Antibiotics: } \\
\hline Yes & $72(100.0)$ & $25(100.0)$ & - & - & - \\
\hline $\mathrm{N} \geq 2$ & $50(69.4)$ & $14(56.0)$ & 0.32 & 1.79 & $0.63-5.03$ \\
\hline \multicolumn{6}{|l|}{ Invasive equipment: } \\
\hline $\mathrm{N} \geq 2$ & $55(76.4)$ & $14(56.0)$ & 0.09 & 2.54 & $0.88-7.39$ \\
\hline Respirator & $16(22.2)$ & $6(24.0)$ & 0.90 & 0.90 & $0.28-3.04$ \\
\hline Surgery & $51(70.8)$ & $15(60.0)$ & 0.45 & 1.62 & $0.57-4.62$ \\
\hline
\end{tabular}

$\mathrm{P}$ - probability of a difference; OR - odds ratio; CI - Confidence Intervals. 
Table 3. Risk factors of hospitalized elders patients at the UFU-HC, with or without nosocomial infections

\begin{tabular}{|c|c|c|c|c|c|}
\hline \multirow[t]{2}{*}{ Risk factors } & \multicolumn{2}{|c|}{ Nosocomial infections } & \multirow[t]{2}{*}{$\mathbf{P}$} & \multirow[t]{2}{*}{$\mathbf{O R}$} & \multirow[t]{2}{*}{ CI } \\
\hline & Yes $(\mathrm{N}=25)$ & No $(N=95)$ & & & \\
\hline \multicolumn{6}{|l|}{ Intrinsic } \\
\hline \multicolumn{6}{|l|}{ Sex: } \\
\hline Female & $8(32.0)$ & $44(46.3)$ & 0.28 & 0.55 & $0.19-1.51$ \\
\hline Male & $17(68.0)$ & $51(53.7)$ & & & \\
\hline Age (years) & $72.96 \pm 7.21$ & $73.56 \pm 6.81$ & 0.69 & - & - \\
\hline $\begin{array}{l}\text { Duration of } \\
\text { hospitalization (days) }\end{array}$ & $18.68 \pm 9.17$ & $9.74 \pm 3.69$ & 0.0007 & - & - \\
\hline \multicolumn{6}{|l|}{ Extrinsic } \\
\hline \multicolumn{6}{|l|}{ Antibiotics: } \\
\hline Yes & $25(100.0)$ & $12(12.6)$ & $<0.0001$ & ND & ND \\
\hline $\mathrm{N} \geq 2$ & $14(56.0)$ & - & $<0.0001$ & ND & ND \\
\hline \multicolumn{6}{|l|}{ Invasives Devices: } \\
\hline $\mathrm{N} \geq 2$ & $14(56.0)$ & $27(28.4)$ & 0.01 & 3.21 & $1.18-8.76$ \\
\hline $\begin{array}{l}\text { Indwelling urinary } \\
\text { catheter }\end{array}$ & $13(52.0)$ & $20(21.0)$ & 0.004 & 4.06 & $1.46-11.39$ \\
\hline $\begin{array}{l}\text { Mechanical } \\
\text { ventilation }\end{array}$ & $6(24.0)$ & $1(1.0)$ & 0.0002 & 29.68 & $3.20-693.56$ \\
\hline \multicolumn{6}{|l|}{$\begin{array}{l}\text { Intravascular } \\
\text { catheter: }\end{array}$} \\
\hline Peripheral & $16(64.0)$ & $48(50.5)$ & 0.32 & 1.74 & $0.64-4.78$ \\
\hline Central & $9(36.0)$ & $8(8.4)$ & 0.001 & 6.12 & $1.82-20.96$ \\
\hline Surgery & $15(60.0)$ & $29(30.5)$ & 0.01 & 3.41 & $1.26-9.39$ \\
\hline
\end{tabular}

$\mathrm{P}$ - probability of a difference; $\mathrm{OR}$ - odds ratio; $\mathrm{CI}$ - Confidence Intervals.

Table 4. Distribution of Adults and Elderly patients with nosocomial infection by clinics/services defined by surveillance in wards

\begin{tabular}{lccc}
\hline Clinics/Services & $\begin{array}{c}\text { Adults } \\
\mathbf{N = 7 2}(\boldsymbol{\%})\end{array}$ & $\begin{array}{c}\text { Elderly } \\
\mathbf{N = 2 5}(\boldsymbol{\%})\end{array}$ & P \\
\hline Surgical & $48(66.7)$ & $14(56.0)$ & 0.47 \\
Intensive Care Unit & $14(19.4)$ & $2(8.0)$ & 0.22 \\
Medicine & $5(6.9)$ & $4(16.0)$ & 0.22 \\
Emergency Unit & $4(5.5)$ & $3(12.0)$ & 0.36 \\
Others & $1(1.4)$ & $2(8.0)$ & 0.16 \\
\hline
\end{tabular}

$\mathrm{P}$ - probability of a difference. 
Table 5. Prevalence of Nosocomial Infections according to anatomical site affected in hospitalized adults and elderly patients at the UFU-HC

\begin{tabular}{lccc}
\hline Site & \multicolumn{2}{c}{ Nosocomial Infection } & P \\
\cline { 2 - 4 } & Adults (N=72) & Elderly(N=25) & \\
\hline Surgical & $34(47.2)$ & $14(56.0)$ & 0.60 \\
Blood & $5(6.9)$ & $2(8.0)$ & 1.00 \\
Lung & $20(27.8)$ & $6(24.0)$ & 0.91 \\
Skin & $5(6.9)$ & $2(8.0)$ & 1.00 \\
Urinary tract & $7(9.7)$ & $1(4.0)$ & 0.67 \\
Others & $3(4.2)$ & -- & 0.56 \\
Unknown & -- & -- & - \\
\hline
\end{tabular}

$\mathrm{P}$ - probability of a difference.

extrinsic risk factors of infection. The larger proportion of the adult population (19.4\%) versus elderly $(8.0 \%)$ that were in the intensive care unit, and the relatively small number of patients included in our investigation may have affected these results. Nevertheless, considering just the elderly group with and without nosocomial infections, we found that the use of $\geq 2$ antibiotics, $\geq 2$ invasive devices, vesical catheters, respirators, central vascular catheters and surgery were associated with acquired hospital infection in the elderly. The length of hospitalization, which is a well-known risk factor that is related to disease severity and affects hospital costs [10], was also a risk factor for the development of HAI; it was twice as long $(\mathrm{p}=0.007)$ in patients with HAI, compared with patients who did not have HAI.

The misuse and overuse of antibiotics in Brazilian hospitals is a major problem $[11,12]$. In our study $42.0 \%$ of the elderly patients were taking antibiotics and $37.0 \%$ of them were on two or more medications. Several studies have shown that certain infections, mainly urinary tract infections and lower respiratory tract infections, occur more frequently in elderly patients [2]. Symptomatic and asymptotic urinary tract infections are much more common among these patients [3]. However in our survey, only $4 \%$ of the hospital infections were classified as urinary. The definition of these infections is difficult, since most of them are asymptomatic and because microbiological data are lacking for most of the patients .

In conclusion, although the nosocomial infections were more common in the elderly patients the difference compared to the under 65 year old adult group was not significant. Even though risk factors such as antibiotic use and invasive equipment were frequent in patients with hospital infection, only $16.5 \%$ of these patients were in critical care units. The most common infections were surgical and lung infections, different from what is reported from industrialized countries, where such infections are most common in intensive care unit patients and in patients with urinary tract infections. This survey is the first to be performed in Brazil and confirms that HAI are common in the elderly, with $16.0 \%$ of our patients developing infection.

\section{References}

1. Beaujean D.J.M.A. Surveillance of nosocomial infection in geriatric patients. J Hosp Infect 1997;36:275-84.

2. Yoshikawa T.T. Epidemiology and unique aspects of aging and infectious diseases. Clin Infect Dis 2000;30:931-3.

3. Thomsons R.B. Infections in the elderly: Issues for the clinical microbiology laboratory. Clin Microbiol News 1999;21:41-4.

4. Ponce de Leon S. The needs of developing countries and the resources required. J Hosp Infect 1991; 18:376-81. 
5. Dean A.G., Dean J.A., Burton A.H., et al. Epi-Info, version 5.0: A word processing database and statistics program for epidemiology on microcomputers. Stone Mountain GA: USD. Ins. 1990.

6. Emori T.G., Banerjee S.N., Culver D.H., et al. Nosocomial infections in the elderly patients in the United States. 1986-1990. Am J Med 1991; 91(3B):289S-93S.

7. Strausbaugh L.J. Emerging health Care-Associated infections in the geriatric population. Emerg Infect Dis 2001; 7:268-71.

8. Ponce-de-Leon S., Rangel-Frausto M.S. Infection control in developing countries. In: Bennett JV, Brachman PS, editors. Hospital Infections. 4th ed. Lippincott - Raven; 1998, p. 291-6.

9. Taylor M.E., Oppenheim B.A. Hospital-acquired infections in elderly patients J Hosp Infect 1998; 38:245-60.

10. Gross P.A., Levine J.F. Infections in the elderly. In: Wenzel RP, editor. Prevention and control of nosocomial infection. 2 nd ed. Baltimore: Willians \& Wilkins; 1993, p.897-923.

11. Wey S.B. Infection control in a country with annual inflation of 3,600s. Infect Control Hosp Epidemiol 1995; $16: 170-4$.

12. Pannuti C.S., Grinbaum R.S. An overview of nosocomial infection in Brazil. Infect Control Hosp Epidemiol 1995; $16: 170-4$. 